\title{
Making 202020 happen: is the hospitality industry mitigating its environmental impacts? The barriers and motivators that German hoteliers have to invest in sustainable management strategies and technologies and their perceptions of online self help toolkits
}

\author{
W. Legrand ${ }^{1}$, C. Kirsche ${ }^{2}$, P. Sloan ${ }^{1} \&$ C. Simons-Kaufmann ${ }^{2}$ \\ ${ }^{1}$ Department of Hospitality Management, \\ International University of Applied Sciences Bad Honnef, Germany \\ ${ }^{2}$ Department of Business and Economics, \\ International University of Applied Sciences Bad Honnef, Germany
}

\begin{abstract}
In 2006, the European Union (EU) set itself the 202020 goal which translates into reducing greenhouse gases by $20 \%$ by the year 2020 compared to 1990 levels. According to the Commission of the European Communities, the 202020 goal can be achieved through measures in energy efficiencies (EE) and an increased use of renewable energy (RE) in the EU's final energy mix to $20 \%$ by 2020. The tourism industry at large is estimated to be responsible for $5 \%$ of the world's carbon dioxide $\left(\mathrm{CO}_{2}\right)$ gas emissions. The hotel sector represents $1 \%$ of all $\mathrm{CO}_{2}$ gas emissions. Some hospitality industry leaders have understood that it makes business sense to modify operations and achieve the economic benefits of sound environmental practice. With multiple incentive programmes in place supporting the 'greening' of operations as well as the plethora of online environmental management self help tools, hotel executives ask themselves what are the barriers and motivators to undertaking investments necessary for mitigating environmental impacts? This study is based on cross-sectional research among German general managers of both privately managed and chainoperated hotels assessing their opinions in regard to barriers and motivators towards investments in green technologies as well as their perceptions of online
\end{abstract}


self-help tools. A majority of the surveyed hoteliers believe that online tools have a potential to encourage hotels to improve their energy efficiency. However, it appears that improved communication regarding available incentives is necessary to counteract the general perception that capital investment is too great in order to undertake meaningful changes in mitigating environmental impacts.

Keywords: mitigating hospitality environmental impacts, barriers, motivators, investment, sustainability, online tools.

\section{Introduction}

The hospitality industry at large and hotel companies in particular have increased their involvement in regards to matters of sustainability during the past decade. Fuelled by increasing energy costs, public scrutiny and regulatory constraints, large-, medium- and small sized hotels are keen on polishing their image while doing something good for the planet [3].

For the past three decades, the oil and chemical industry has long been in the spotlight due to their visible and often negative environmental image [4]. While not in the front seat of environmental pollution and consumption of nonrenewable resources compared to heavy industries, the hospitality industry is often associated to be at the front of the service industry in terms of resource usage [5]. While issues surrounding the management of waste produced or water consumed in hotels are important features of any environmental management programme, carbon dioxide $\left(\mathrm{CO}_{2}\right)$ emissions have taken the central stage in the mitigation of environmental impacts [6]. The partnership formed to develop Carbon Footprint Standards between the International Tourism Partnership (ITP), the World Travel \& Tourism Council (WTTC) and major international hotel players is yet one more recent imitative aimed to make carbon measurement possible [7]. It is important to realize that due to a resource intense utilization of energy, water, and consumables in hotel facilities, the environmental footprint of hotels is typically larger than those of buildings of similar size. This is partly explained by the fact that hospitality operations are made up of a diversity of small operations from restaurants and banqueting to housekeeping and spas. Each of those operations accounts for a rather small share of environmental pollution in terms of energy and water consumption, food, waste and other resources but it is the whole which is greater than the sum of its parts (Aristotle).

With this in mind, numerous hoteliers restructured business practices towards sustainability with an increasing understanding of long-term business prospects and profitability [8], some based on the triple-bottom line principles [9]. Considering the sheer size of the hospitality industry, in terms of economic contribution, expansion plans or employment creation, it has a notable influence on the global economy and finds itself having a significant social, environmental and economic responsibility. 


\section{Motivators and barriers}

Almost two decades ago, research demonstrated that there were significant barriers for hoteliers to invest in sustainability matters such as high capital costs, reservations concerning improved profitability resulting from the implementation of environmental management systems and a general lack of knowledge in environmental issues [10]. Now well into the 21 st century and with constant public attention on environmental issues and with multiple incentive programmes in place supporting the 'greening' of operations as well as the plethora of online environmental management self help tools one can ask have the barriers and motivators to undertaking investments in mitigation of environmental impacts changed? If the answer is yes, what then needs to be done for words to be put into actions?

Post and Altman [10] classified the barriers to environmental adaptations into industrial and organizational barriers. The industrial dimension is influenced by the activities a business carries out and the organizational dimension refers to the business itself. Here, capital costs, competition, regulatory constraints and the lack of information and technical knowledge can be found as being the major barriers to sustainability advancements in the industrial dimension [11]. On the other hand, internal constraints such as employee attitudes, insufficient management leadership, lack of communication and the issue of behavioural patterns resulting from past practice seem to be at the top of corporate barriers to environmental strategy making [11]. Interestingly, modern executives believe that they must decide between social and environmental benefits to sustainability and the costs of implementing such schemes [12]. However, an analysis of 30 major companies clearly showed that sustainability brings organizational and technological innovations with clear long-term cost benefits and additional revenue generation [12]. It is important to stipulate that "fewer hotel businesses recognize the financial benefits associated with the implementation of environmental initiatives" [13]. Indeed, the notion that "sustainability is expensive" is deeply anchored in society and has become a widespread fallacy. However, "market forces have seemingly evolved to a point where sustainable and socially responsible business practices either break even or prove profitable" [14]. Next to the financial aspect, the time invested as well as the management required to implement a sustainability strategy also greatly contribute the resistance felt by hoteliers. Finally, the lack of interest in the topic of sustainability coupled with the missing business relevance are further barriers identified in various researches $[15,16]$.

While the general perception that financial constraints resulting from investing in sustainability is one of the greatest barriers, whereas the possible long-term cost savings as well as the incentives offered to companies investing in green technologies are perceived as strong motivators in three independent studies [16-18]. Companies also embrace sustainability trying to make use of a potential image improvement [19]. A hotel implementing sustainability can also benefit from an improved competitive position when entering a market niche of environmental-friendly products and services [20]. Corporate decision to move 
towards sustainable or responsible management may equally be fostered by ethical motives or institutional pressures or simply by a 'feel-good factor' [21]. Since, overall positive work satisfaction and enhanced employee moral were short-term benefits encountered in companies implementing a sustainability strategy; those components are also considered to be motivators [22].

\section{Online tools}

The development of information technology (IT) contributes towards $2 \%$ of global $\mathrm{CO}_{2}$ emissions [23], the use of IT can equally and heavily contribute to overall reduction in $\mathrm{CO}_{2}$ emissions [24]. Beside the general advantages such as increased efficiencies in all processes in hotels, the hospitality industry can greatly benefits from the use of online content. On that bumpy path to sustainability are some self-help online tools supporting hoteliers in auditing their operations and leading to informed decision making. One of the most recent online tools is the Hotel Energy Solution (HES) online toolkit. The HES toolkit is the result of a partnership between the United Nations World Tourism Organization (UNWTO), the United Nations Environment Programme (UNEP), the International Hotel and Restaurant Association (IH\&RA), the French Agence de l'Environnement et de la Maîtrise de l'Énergie (Environment and Energy Management Agency or ADEME) and the European Renewable Energy Council (EREC). HES seeks to help small and medium-sized hoteliers to measure, analyze and reduce energy consumption and $\mathrm{CO}_{2}$ emissions in their operations [25]. The basic concepts behind HES and other online tools are for hotels to enter specific details into the online tool, including: occupancy rate, energy usage, energy costs, resources used maintaining the buildings, and efforts already undertaken to improve sustainability to name but a few. The tools consequently evaluate energy efficiency and the respective carbon footprint created by the hotel(s). In addition, tips and recommendations for investment with estimated returns on investment are presented, helping the managers and owners of hotel properties achieve a higher level of energy efficiency. Online self reporting software also serves as an industry benchmarking tool.

\section{Study aim}

This study aims are threefold: (1) to contrast the motivators and barriers to investments in green technologies and strategies identified in the literature to those collected by primary research in order to forward the body of knowledge on the subject (2) to analyse the perceptions of hoteliers towards online self-help tools and (3) to formulate a set of recommendations on the potential of online self-help tools as a guiding mechanism for improvement towards mitigating environmental impacts. 


\section{Methodology}

This study conducted email surveys to gather the necessary data while structured questionnaires were used as the instrument of assessing the opinions of hotel managers in regard to barriers and motivators in investing in green technologies and strategies as well as the potential of online self-help tools that mitigate environmental impacts. A two-stage approach entailing qualitative and quantitative research techniques was implemented. Several personal interviews were first conducted with experts, including 5 general managers in the region of Bonn, Germany. Those hoteliers were also participating in the pilot-testing of the HES online toolkit and were deemed to be aware of current issues regarding selfhelp online tools. The goal of expert interviews was mainly to solicit general opinions pertaining to the structure, length, wording and content of the questionnaire.

\subsection{Questionnaire development}

The questionnaire encompasses four sections in all in line the objectives of this study. In the first section and following an introductory text summarizing the aim of the research and the importance of the hotelier's contribution, the general attitude of hoteliers towards sustainability was addressed in combination with a question about recent sustainability investments. A 5-point Likert-scale was used to assess the importance of five impulsive statements anchored by strongly disagree/strongly agree. In the second section of the questionnaire, opinions on the awareness of online tools are collected, including questions which address the desire of hoteliers to make use of online self-help tools in order to evaluate energy efficiency and mitigate environmental impacts. The third section addresses the motivators and barriers for investments in sustainability. Finally, the fourth section draws back on the topic of online tools, by asking hoteliers their thoughts on the future of self-help online tools.

\subsection{Sampling technique}

An opportunity sample with elements of probability sampling was used. A database of general managers of hotels was used to randomly pick hotels in Germany. The sampling frame of this research contains 2500 general managers based in Germany. 280 questionnaires were sent out to randomly picked members. In total, 55 valid responses where received, resulting in a $19.4 \%$ response rate. These respondents may be referred to as hoteliers or general managers in describing the person who has answered the questionnaire.

\section{Findings}

The data collected is expressed by charts and simple statistical illustrations such as means and frequencies. For the purpose of this study, only two sections of the questionnaire are presented those being (1) motivators and barriers to invest in sustainability, and (2) the potential of online self-help tools. 


\subsection{Motivators and barriers for hoteliers to invest in sustainability}

In order to evaluate the motivators and barriers, information was collected from hoteliers on whether sustainability investments had already been made by their individual hotels in recent years. A total of 48 out of $55(87 \%)$ German hoteliers had undertaken investments that enhanced the sustainability standpoint of their hotel. In more detail and as shown in Figure 1, 44 hoteliers of the 48 (91\%) stated that investments were made to enhance energy efficiency, 30 hoteliers invested in process optimization, 20 hoteliers $(40 \%)$ pointed out that investment in recycling were made and 17 hoteliers $(35 \%)$ worked on waste reduction strategies. 12 hoteliers (24\%) incurred expenditures on sustainable architecture. Hoteliers had the opportunity to clarify other types of investments completedThose mentioned are (in no order to preference): education and training for employees, procurement procedure focusing on locally sourced products, the adoption of rain barrels as well as the implementation of fair trade procurement.

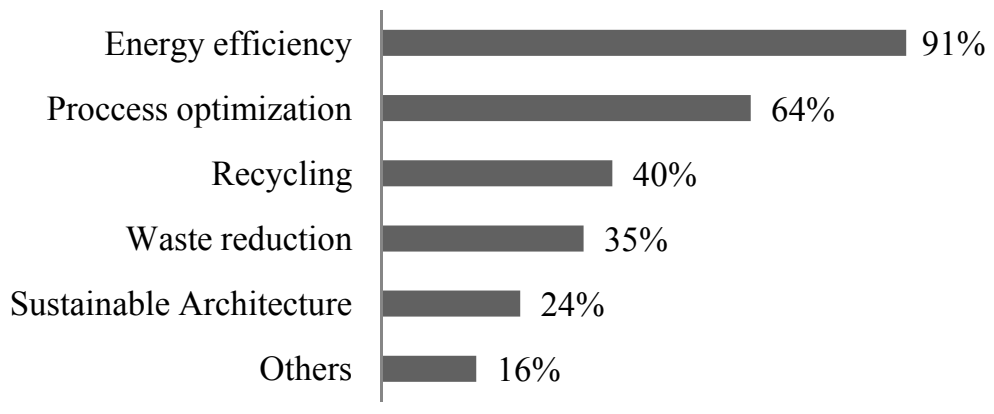

Figure 1: Areas of investment.

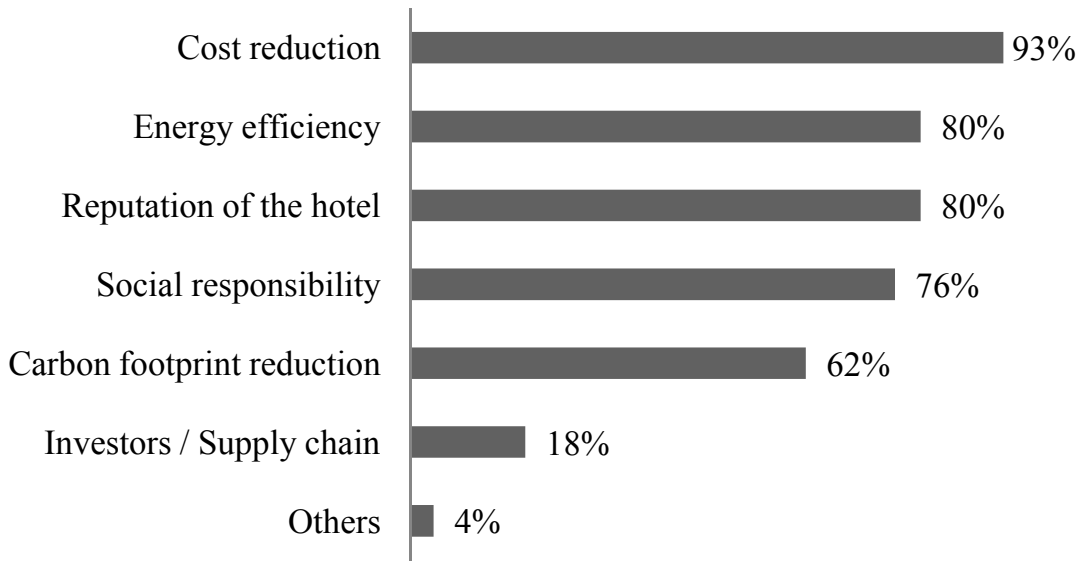

Figure 2: Motivators for hoteliers to invest in sustainability. 
As shown in Figure 2, the overall cost reduction is the key motivator for hoteliers to undertake investments which enhance the sustainability performance of their hotels. 51 out of 55 responses (93\%) selected cost reduction as a driver. Improvements in the area of energy efficiency as well as the overall increase in reputation of hotels engaged in sustainability were chosen equally by 44 hoteliers as the second most important motivators. Social responsibility is a motivator in $76 \%$ of the cases. 34 hoteliers $(62 \%)$ see the reduction of the $\mathrm{CO}_{2}$ emission as a key driver for sustainable investments.

A minority of hoteliers see the interaction with investors and possible cooperation along the supply chain as important motivators for investment in sustainability matters. Two respondents took the opportunity to formulate alternative motivators to the pre-listed ones. One hotelier stated that maintaining the resources and providing for the needs of future generations is a motivating element. One other hotelier answered that guest requests can be considered as driving the hotelier to adopt sustainability features.

Similar to the motivators, the barriers that hoteliers are facing when considering investments in sustainability were explored with a pre-set of possible answers presented and where multiple answers were possible. For barriers which hoteliers encountered but did not find in the list, 'Others' provide the opportunity to express such occurrence in more detail.

As presented in Figure 3, the most dominant threat to sustainability investments is the lack of financial means with $71 \%$ of total responses, equal to 39 hoteliers out of 55 . Some 33 hoteliers $(60 \%)$ still question the profitability of sustainability investments. The complexity of implementing sustainability approaches is a barrier for roughly half of the respondents. Closing the list of possible barriers to investments are the missing business drivers, the lack of staff available for implementing new concepts, the lack of local relevance for engaging

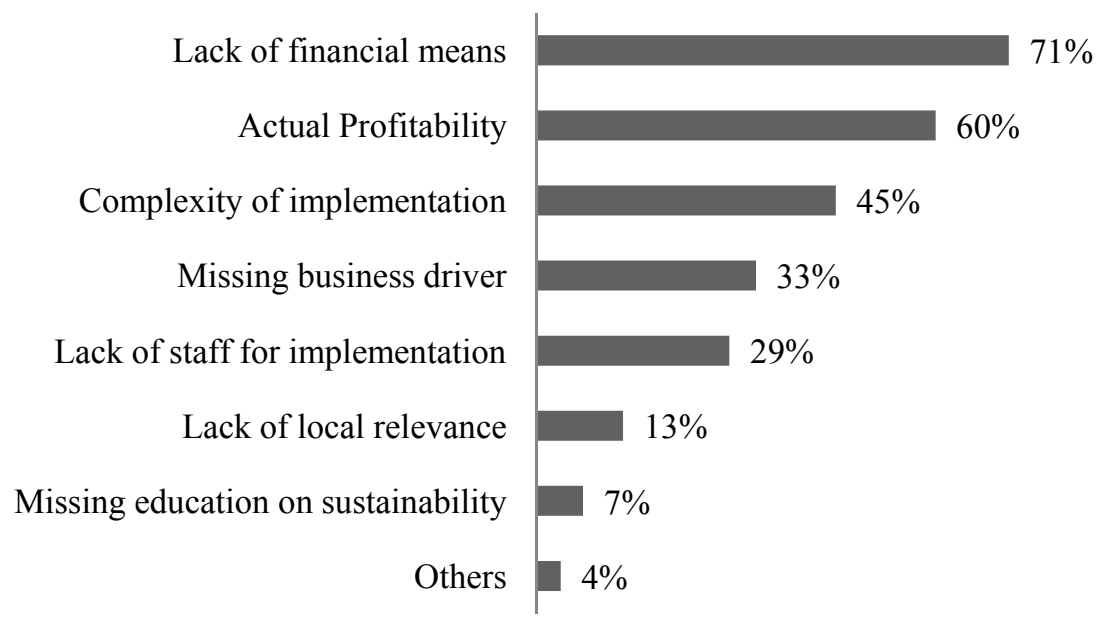

Figure 3: $\quad$ Barriers for hoteliers to invest in sustainability. 
in sustainability improvements and insufficient education on sustainability matters. Similar to the motivators, two respondents took the opportunity to formulate alternative barriers to the pre-listed ones. One hotelier stated that the attitude of the building owners is a potential threat for realizing sustainability improvements. The second hotelier expressed that being a member of a hotel chain, the leeway for creativity is limited to guidelines and decisions made by headquarters.

\subsection{Potential of online self-help tools}

In this section, questions were posed as to whether hoteliers would ever consider an online tool for evaluating energy efficiency in their hotels. From 55 respondents, 44\% answered this question with 'Yes', 42\% with 'Unsure' and $15 \%$ said that they would not make use of such an online tool. The following question explored how hoteliers feel about the reliability of the results on energy efficiency and the carbon footprint calculations of online self-help tools. More than half of the surveyed hoteliers (56\%), stated that they are confident about the results online tools can calculate. Five out of 55 respondents reported they would not trust in the results of online tools and the remaining $35 \%$ were unsure about their potential. $71 \%$ of the hoteliers agreed to the usefulness of such tool to increase (1) the awareness of sustainability, (2) to evaluate environmental performance of the hotel and (3) to give further recommendations for improvements to the individual hotels. $27 \%$ expressed that they were unsure about the potential and a remaining $2 \%$ did not see the usefulness of such tool. Some hoteliers argued that evaluating energy efficiency with a tool such as HES is a good place to start, but does not represent the whole picture of sustainability in the hospitality industry.

\section{Discussion}

The majority of hotels have recognized the importance of incorporating sustainability principles within their operations that have led to green investments in recent years as demonstrated by secondary research and supported by this exploratory study. Those investments vary from LED lighting, to motion sensors connected to the light intensities, up to cogeneration plants for heating purposes. Some hoteliers do, however, face certain limits of implementing sustainability when it comes to the ownership of the buildings. In some cases where the hoteliers have leased the building in which they operate, the building owners may restrict the hoteliers from modifying structural components such as the roof or walls.

\subsection{On motivators}

Key drivers for sustainability investments are lowering overall costs and conversely, hoteliers perceive the cost issues as one of the main barriers to investment. Hoteliers seem to be in a typical causality dilemma whereby money must be invested in order to save money. This exploratory study shows that the potential of cost savings and the improvement of energy efficiency are the 
primary motivators. The increased energy costs for hoteliers over the past decade may explain the increased importance of the 'energy efficiency' factor as a motivator for investment. The enhanced reputation of hotels undertaking sustainability initiatives plays a major role in motivating hoteliers. With increased public scrutiny, it does not come as a surprise that positive activities are rewarded with peer and consumer recognition.

\subsection{On barriers}

This exploratory study provides similar data to previous research whereby a clear majority of respondents stating that the lack of financial means is a predominant barrier to investments in sustainability. The barrier is even bigger when coupled with the hoteliers' uncertainty on the profitability potential of sustainability investments in the long-term. There seems to be a need for clearer information on the return on investment of each option linked to sustainability so that hoteliers can make informed decisions. It was found that hoteliers would be willing to make use of online self-help tools to evaluate their hotel's energy efficiency.

\subsection{On self-help online tools}

There is a real scarcity of information in regards to the value and use of online self-help tools in particular relating to the hospitality sector. Hoteliers that already had experience with online self-help tools were members of a hotel chain with internal evaluation programs. The opinion about such tools varies strongly among the hoteliers. This study provides is a clear indicator that online tools have a potential to help in mitigating environmental impacts via measurement and recommendations but there is a definite need for information and education on both the technicalities and possibilities offered by those online tools.

\section{Recommendations, limitations and future research}

The potential for the hospitality industry in becoming environmentally friendly is enormous. From waste reduction programmes to water saving techniques, from energy efficient technologies to employee training, much resides in the hands of the managers in the daily operations. However, for larger investments such as building technologies, green technologies, refurbishment and remodelling, barriers and motivators play an important role in the final investment decisions. While a few hoteliers may have the luxury of intrinsic motivation towards sustainability, for the larger share of hoteliers, implementing sustainability is driven by profit margins. Many have realised that combining environmental stewardship and business strategy is a driver for economic value. There are multiple governmental incentives and preferred loan models available, however information about those must communicated. National hotel associations can provide the necessary support in that area by organising topical informative sessions. As demonstrated in this exploratory study, with energy prices on the rise, there is automatically a strong incentive for sustainability advancements in 
the context of reducing the overall energy usage. In order for hoteliers to make informed decisions about investing in energy efficiency technologies and potentially renewable energy sources, a clear understanding of the current energy usage is necessary. This is where free-of-charge self-help online tools such as the HES can help hoteliers. By entering current data on energy usage and basic data about the hotel property and service, the tool performs a series of calculations leading to a relatively clear benchmarked picture and energy performance of the building. One design concept of such tool is to bypass consultants and their fees in the first phase of analysis since this can be completed by the hotelier or chief engineer at property. Since the majority of respondents could not name any online evaluation tool currently operating, there is a clear need for information and education. Local, regional or national hotel associations should embark on information campaigns directed at hoteliers on energy consumption and the use of similar online evaluation tools. Since the majority of respondents have trust in the power of such tools, there needs to be a system of assistance in place, in forms of online videos for example. The authors recommend developing a tool which goes beyond energy efficiency and carbon footprints to include more environmental factors and the social dimensions of sustainability. Improved benchmarking across hotel categories and geographical location is also a feature needed, thus, enabling hoteliers to learn from each other and share knowledge, experiences and ideas.

\subsection{Limitations}

This research is exploratory in its nature and holds a certain number of limitations. The selection of the sample has a major influence on the potential of generalizing results. In non-probability samples, the general application is regarded as unreliable since not every member of the target population had an equal chance of being selected. The content of the questionnaire was mainly influenced by the literature review with some sources published a decade ago. In the field of sustainability, barriers and motivators may change rapidly depending on the economic and or political situation within a country. Questions relating to the online self-help tool are difficult to analysis since some hoteliers were just not aware of the existence of online self-help tools. Most of the questions on online self-help tools are limited to energy efficiency and carbon footprint calculations. Therefore, the focus is only on just a few aspects of sustainability and not on a wide range of topics which could have included waste reduction and water consumption.

\subsection{Future research}

In a first stage, future research should assess the effect online self-help tools have on barriers and motivators for hoteliers in implementing sustainability at their hotels. In a second stage, research could evaluate what effect online tools really have on the actual investment decisions and the knock-on effect of those investments in terms of savings, reputation, image and so on. 


\section{References}

[1] Commission of the European Communities. Energy efficiency: delivering the $20 \%$ target, Communication from the Commission, Brussels, http://eurlex.europa.eu/LexUriServ/LexUriServ.do?uri=COM:2008:0772:FIN:EN:P $\mathrm{DF}$

[2] UNEP-UNWTO. Tourism: Investing in energy and resource efficiency. http://www.unep.org/greeneconomy/Portals/88/documents/ger/GER_11_To urism.pdf

[3] Ernst and Young. Hospitality going green. http://www.ey.com/Publication /vwLUAssets/Global_Hospitality_Insights__a_publication_for_the hospitality_industry_-\$ \$FILE/Global\%20Hospitality\%20Insights.pdf

[4] Brown, M., Environmental policy in the hotel sector: "green" strategy or stratagem? International Journal of Contemporary Hospitality Management, 8(3), pp. 18-23, 1996.

[5] Sloan, P., Legrand, W. and Chen, J.S., Sustainability in the Hospitality Industry: Principles of Sustainable Operations. Butterworth-Heinemann: Oxford, 2009.

[6] Zientara, P. and Bohdanowicz, P., The hospitality sector (Chapter 5). Bridging Tourism Theory and Practice, eds. Jafar, J. and Liping, A. C., Emerald Group Publishing Limited, pp. 91-111, 2010.

[7] ITP. Major international hotel companies demonstrate leadership through new initiative to standardise the industry's carbon measures. http://www.tourismpartnership.org/media-centre/23-major-internationalhotel-companies-demonstrate-leadership-through-new-initiative-tostandardise-the-industrys-carbon-measures

[8] Bader, E. E., Sustainable hotel business practices. Journal of Retail \& Leisure Property, 5(1), pp. 70-77, 2005.

[9] Elkington, J., Cannibals with Forks: The Triple Bottom Line of 21st Century Business, New Society Publishers, 1998.

[10] Post, J.E. and Altman, B.W., Managing the Environmental Change Process: Barriers and Opportunities, Journal of Organizational Change Management, 7(4), pp. 64-81, 1994.

[11] Murillo-Luna, J. L., Garcés-Ayerbe, C., and Rivera-Torres, P., What Prevents Firms from Advancing in their Environmental Strategy? International Advances in Economic Research, 13(1), pp. 35-46, 2007.

[12] Nidumolu, R., Prahalad, C.K. and Rangaswami, M.R., Why Sustainability Is Now the Key Driver of Innovation. Harvard Business Review, 2009.

[13] Graci, S., and Dodds, R., Why Go Green? The Business Case for Environmental Commitment in the Canadian Hotel Industry. Anatolia: An International Journal of Tourism \& Hospitality Research, 19(2), pp. 251270, 2008.

[14] Sneirson, J. F., Green Is Good: Sustainability, Profitability, and a New Paradigm for Corporate Governance. 2009. http://www.uiowa.edu/ ill /issues/ILR_94-3_Sneirson.pdf 
[15] Hobson, K., and Essex, S., Sustainable Tourism: A View from Accommodation Businesses. Service Industries Journal, 21(4), pp. 133146, 2001.

[16] Sloan, P., Legrand, W. and Chen, J. S., Factors influencing German hoteliers' attitudes toward environmental management. Advances in Hospitality and Leisure, 1, pp. 179-188, 2004.

[17] Bohdanowicz, P., Greening the Business: European Hoteliers' Environmental Attitudes. Cornell Hotel \& Restaurant Administration Quarterly, 46(2), pp. 188-204, 2005.

[18] Miller, R. K., and Washington, K., Green \& Sustainable Hospitality (Chapter 6). Hotels \& Resorts, eds. Miller, R.K. \& Associates, pp. 156-160, 2009.

[19] Lubin, D. A., and Esty, D. C., The sustainability imperative. Harvard Business Review, 88(5), pp. 42-50, 2010.

[20] Graci, S., and Dodds, R., Why Go Green? The Business Case for Environmental Commitment in the Canadian Hotel Industry. Anatolia: An International Journal of Tourism \& Hospitality Research, 19(2), pp. 251$270,2008$.

[21] Hahn, T., and Scheermesser, M., Approaches to corporate sustainability among German companies. Corporate Social Responsibility \& Environmental Management, 13(3), pp. 150-165, 2006.

[22] Bansal, P., and Roth, K., Why Companies Go Green: A Model of Ecological Responsiveness. Academy of Management Journal, 43(4), pp. 717-736, 2000.

[23] Boccaletti, G., Löffler, M., and Oppenheim, J.M., How IT can cut carbon emissions.

http://www.mckinseyquarterly.com/How_IT_can_cut_carbon_emissions_2221

[24] Ertel, S., WWF Studies Find Information Technology Significantly Reduces Climate Impacts, Costs Of Doing Business. http://www.worldwildlife.org/who/media/press/2009/WWFPresitem11941. html

[25] HES (2011). Supports the adoption of energy efficiency and renewable energy technologies. http://hes.e-benchmarking.org/ 